\title{
Canadian Lung Association Research Program
}

$\mathrm{T}$ he Canadian Lung Association (CLA) would like to share some information with the members of its professional societies about some difficult decisions that were made which have affected its research program this fiscal year. These actions were taken to ensure the growth and sustainability of the CLA research program.

The CLA is a partnership of 10 provincial lung associations. Our vision is "all people free of lung disease", and our mission is to lead nationwide and international lung health initiatives to prevent lung disease, help people manage lung disease and promote lung health.

Research support is a major focus of the CLA and its provincial partners. Together, we have funded respiratory research for over 30 years; we give at a current rate of over $\$ 5$ million/year via two programs: a national funding program for training and several provincial research funding programs.

The national research fund, which is generated from a yearly assessment from the 10 member provinces plus bank interest, has been declining during the past several years because we have continued to provide grant funding in excess of our annual income. We have been working on ways to ensure its sustainability into the future. Discussions have taken place among the CLA board of directors; chief executive officers from the provincial lung associations; executive members of the Canadian Thoracic Society (CTS), the Canadian Nurses Respiratory Society (CNRS), the Canadian Physiotherapy Cardio-respiratory Society (CPCRS) and Respiratory Therapy Society (RTS); and CLA staff concerning the CLA research fund. The discussions culminated in a facilitated workshop to confirm future plans, held this past August.

In December 2000, one of the provincial Lung Associations faced severe financial difficulties, to the point that it was unable to make either its research or operations assessments to the CLA; it has not been able to do so for for the past one and one-half years. This has affected the research fund; however, we continued to operate the program while we considered various options. That association is not yet able to repay its debt to the CLA and has only just begun paying its current assessment, at a reduced rate, as of April 1, 2002.

In March 2002, the CLA was informed by another member that it, too, was facing financial difficulties and would be unable to pay both its research and operations assess- ments for the coming year. The CLA had not foreseen this. The impact on the CLA's budget was substantial, to the point that $25 \%$ of the research and operations budgets were affected. Added to the first association's inability to make its payments to the CLA, the full effect on our budgets was crippling.

The board asked staff to review the impact on

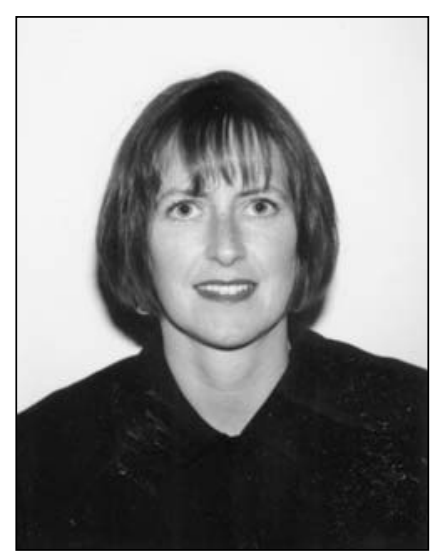

Deirdre Freiheit the budgets, in concert with the board's finance committee. Decisions were made to cut everywhere possible and to prepare for a rebuilding period during the coming year. Revised operations and research budgets were presented to the board for consideration on May 23, 2002, almost two months into the new fiscal year.

The board then made one of the most difficult decisions that it has ever had to make. Funding cuts were made to the operating budget to the extent that programs were severely affected. A decision was made to meet existing research commitments and not to offer any new awards to the CTS, CNRS and CPCRS. The decision was not taken lightly and was made only after every possible alternative option had been considered.

Since making this decision, we have been informed by some of our research partners in the pharmaceutical industry and the Canadian Institutes for Health Research that they will provide funding this year for the six new CTS research fellowships that the CLA originally intended to fund in partnership. This means that the CTS grants will be awarded this year.

The CLA research program is a high priority of the association and the board of directors. Our intention is to continue to provide funding for new research next year. Because it is so important to the CLA, its research and finance committees are currently working on options for building the research fund to an acceptable and sustainable level that will not be jeopardized in the future.

Had the CLA and its board not made this decision this year, the research fund would have been depleted further, 
and in roughly four to five years, it would not exist. The board felt that it had a responsibility to the research community to address this problem once and for all.

All of the societies and their respective research chairs have been asked to participate on the research committee, which will make recommendations to the CLA board in October 2002, while the new budget for fiscal 2003/2004 is developed.

With proper planning today, the CLA will not have another year in which it must make cuts to the research program. We extend our apologies to those who applied for funding this year, knowing the tremendous amount of time and energy that goes into completing our research applications.

We have built excellent relationships with our industry partners, and we are extremely pleased that they will sup- port us in this way during this time of financial constraint. We will be working with them during the coming year to look at new and innovative ways to fund research and create new partnerships.

The CLA is very proud of the research that it has funded during the past 30 plus years. The board and staff will be working hard this year to begin the process of rebuilding the fund.

We look forward to providing research funding to the respiratory health community for many years to come.

Deirdre Freiheit President and Chief Executive Officer Canadian Lung Association 


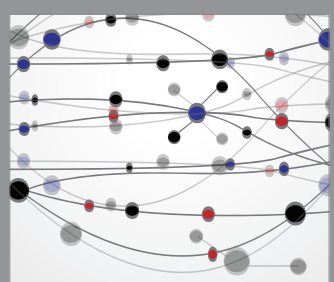

The Scientific World Journal
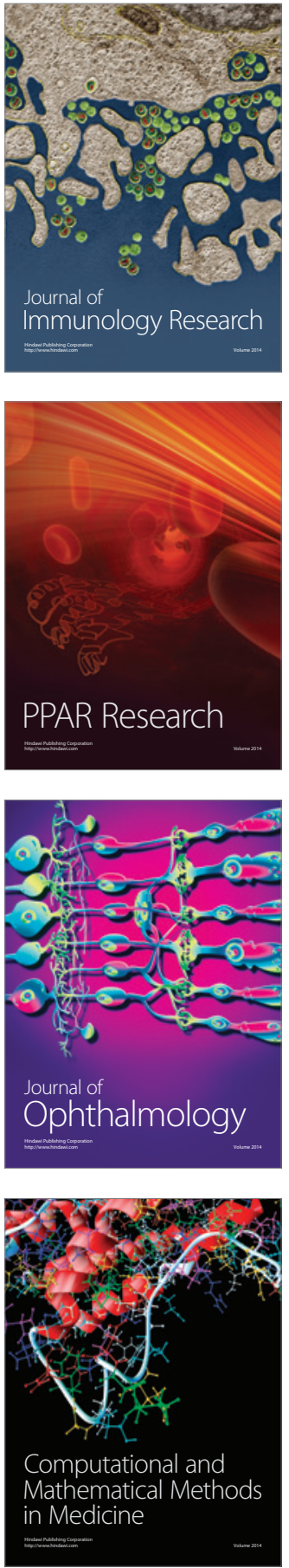

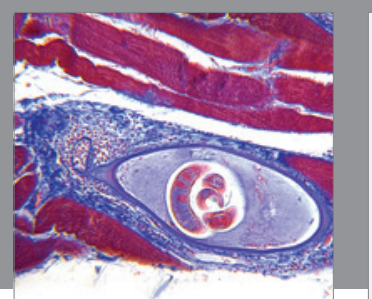

Gastroenterology Research and Practice

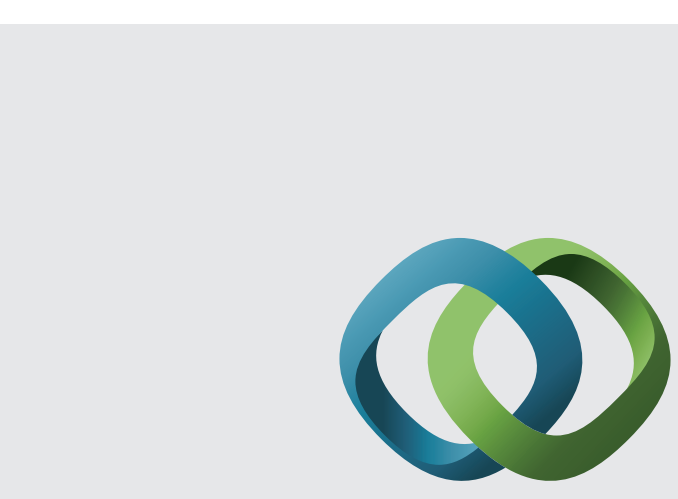

\section{Hindawi}

Submit your manuscripts at

http://www.hindawi.com
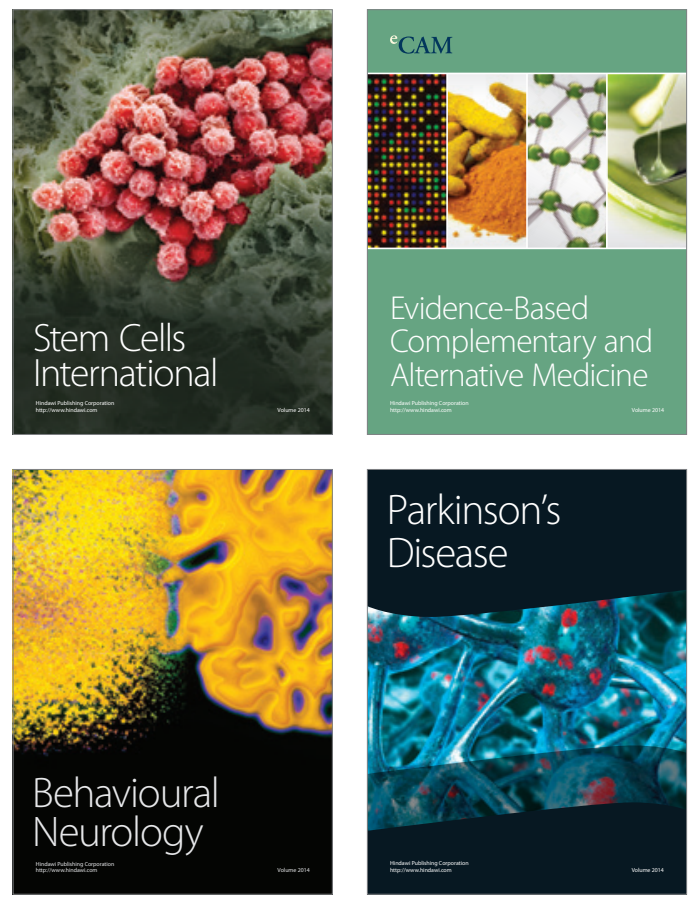
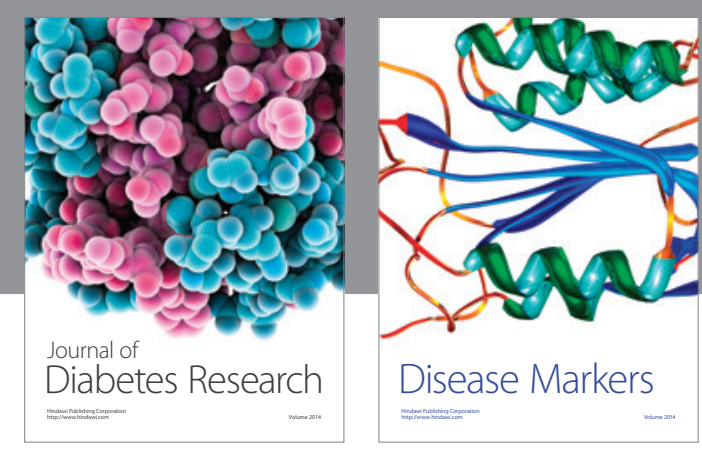

Disease Markers
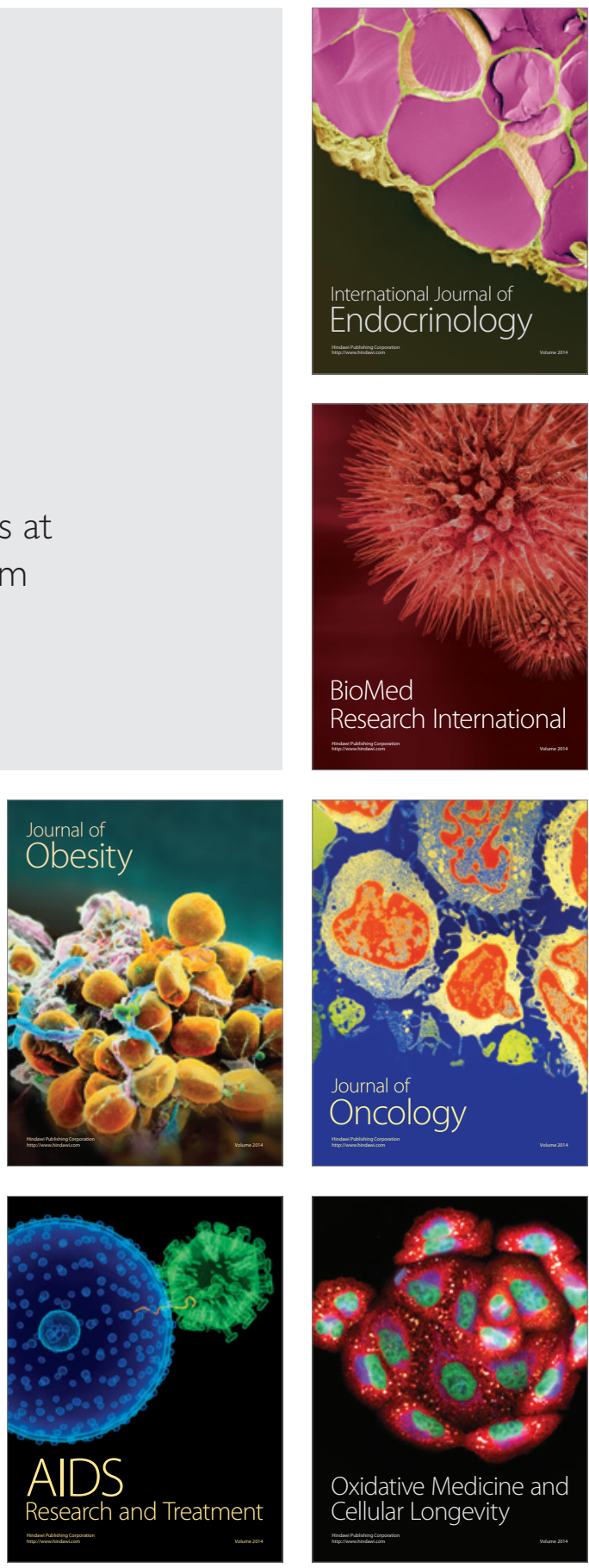